NASA Technical Memorandum 83760

\title{
Analysis of the Effect on Combustor Noise Measurements of Acoustic Waves Reflected by the Turbine and Combustor Inlet
}

Ronald G. Huff

Lewis Research Center

Cleveland, Ohio

Prepared for the

Ninth Aeroacoustics Conference

cosponsored by the American Institue of Aeronautics and Astronautics and NASA Williamsburg, Virginia, October 15-17, 1984 


\author{
Ronald G. Huff \\ National Aeronautics and Space Administration \\ Lewis Research Center \\ Cleveland, Ohio 44135
}

\section{Abstract}

Spectral analyses of static pressure fluctuations measured in turbine engine combustors at low engine speed show good agreement with theory. At idle speed the high pressure turbine is unchoked. Above idle speed the turbine chokes and a significant change in the shape of the measured combustor pressure spectrum is observed. A simplified theoretical model of the acoustic pressure generated in the combustor due to the turbulence-flame front interaction did not account for acoustic waves reflected from the turbine. By retaining this simplified combustion noise source model and adding a partial reflecting plane at the turbine and combustor inlet, a simple theoretical model has been developed that reproduces the undulations in the combustor fluctuating pressure spectra. Plots of the theoretical combustor fluctuating pressure spectra are compared to the measured pressure spectra obtained from the CF6-50 turbof an engine over a range of engine operating speeds. Reasonable agreement exists, and it is thus concluded that the simplified combustion noise theory when modified by a simple turbine reflecting plane adequately accounts for the changes in measured combustor pressure spectra. It is further concluded that the shape of the pressure spectra dcwnstream of the turbine, neglecting noise generated by the turbine itself, will be the combustion noise spectra essentially unchanged except for the level reduction due to the energy blocked by the turbine.

\section{Introduction}

The reduction of aircraft noise through the use of high-bypass-ratio turbof an engines has revealed another noise source for concern: core engine noise. Core engine noise is defined as the noise produced by the gas generator-turbine$t a i l p i p e$ combination used to provide shaft power to drive the fan in a turbofan engine. Reference 1 summarizes various combustion noise prediction methods for aircraft engines available before 1974 . The methods include both engine and combustor rig predictions.

More recently it has been recognized that gas generators in earth to orbit propulsion systems create fluctuating pressures that load structures and contribute to high cycle fatigue failure of critical structures. When prediction of the gas generator fluctuating pressure is required to determine high cycle loading the methods used to calculate core engine noise can be applied.

Since the publication of Ref. 1 a data bank from various combustion noise experiments has been created by NASA. 2-9 Additionally 19 number of engine tests have been performed $10-19$ to determine the amount of core engine noise reaching the farfield observer. The acoustic power determined from the data in Refs. 2 to 9 has been correlated with engine operating parameters in Ref. 20. A number of theoretical investigations is reported in the literature: Ref. 21 sets forth several possible combustion noise source terms to be evaluated; Ref. 22 gives a correlation of data, based on theory, for the acoustic power in a combustor with engine operating parameters; Ref. 23 gives scaling laws for combustion noise radiating from open flames that are based on a theory evolved by using the chemical reactions; Ref. 24 calculates the 1/3-octave spectrum for a propane-air open flame; and Ref. 25 points out the need to know the heat release distribution in the combustor before the dynamic design can be performed. References 21 to 24 have focused attention on combustion noise theory and have presented a fundamental, though at times complex, picture of possible combustion noise mechanisms. Reference 26 has shown that the combustor fluctuating temperatures and pressures are correlated in ducted burners, that heat release distribution is important and that the fluctuating volumetric heat release rate needs to be investigated as a source term in combustion generated noise.

In an effort to understand the dominant combustion noise mechanism and to provide a theoretically based prediction that allows insight into the noise-generating parameters in ducted combustors, a simple combustion noise model was derived in Ref. 27. The fluctuating pressure spectrum generated by the interaction of the turbulence with the mean energy gradient in a burner connected to infinite ducts (no reflected waves in either direction) was determined analytically and compared to pressures measured in a CF6-50 turbof an engine combustor. While-good agreement existed between data and the theory, deviations existed above engine idle condition that need to be explained. In the derivation of the acoust ic source pressure in Ref. 27 the effect of acoustic waves reflected from both the turbine and combustor in let planes was neglected.

The objective of the present work is to provide a theoretical solution for the acoustic pressure generated by a turbulent-flame interaction noise source located in a duct between two reflecting planes and to demonstrate that accounting for simple reflections can explain the variation in the narrowband spectral data from the existing theory of Ref. 27. All symbols used herein are defined in Appendix A.

Theoretical Model for Combustion Noise with Reflecting Planes

The model for combustion noise considers a one-dimensional constant area, duct flow (Fig. 1). The flow is composed of a mixture of fuel and air. Turbulence is generated upstream of the flame front by turbulators. The flame front is stabilized aerodynamically at a point just downstream of the turbulators but does not touch the turbulators. 
The source region of combustion-related noise starts at the flame front. To simplify the calculations, the flame front is considered to be in a plane perpendicular to the flow direction. The regions upstream and downstream of the source region have constant though different properties and are terminated with partial reflecting planes. In engine combustors the combustion zone temperature varies with axial distance. In this analysis the wave number is assumed constant in the region downstream of the flame front thus neglecting variation in sonic velocity in the combustion zone. he reflecting planes represent the turbine and combustor inlets in a real turbine engine or turbopump.

Inf inite Duct Theory

The narrowband fluctuating pressure spectrum measured in the combustor of the CF6-50 engine has been predicted ysing a simple source theory in an infinite duct. 27 A comparison of the theory with data is shown in Fig. 2 for the engine operating at both low and high thrust. At the idle condition (Fig. 2(a)) the theory and data agree very well if the closely spaced minimum value points in the spectrum are ignored. At the 99.8 percent thrust condition (Fig. 2(b)) deviation of the measured spectra from that predicted from the infinite duct theory is apparent at frequencies around 300 and $1300 \mathrm{~Hz}$. To account for this deviation a theoretical analysis including the effects of reflected waves on the measured spectra has been developed. The model, as expected, does not explain the closely spaced minimum value dips in the spectra.

\section{Reflecting Plane Theory}

The one-dimensional Fourier-transformed acoustic wave. equation with the turbulence-flame front noise source term from Ref. 27 is written here as:

$$
\frac{\partial^{2} p_{\omega}}{\partial x^{2}}+k^{2} p_{\omega}=-\frac{\dot{W}}{A} \frac{\partial^{2}}{\partial x^{2}}\left(\frac{\delta \omega}{o} v\right)
$$

For low Mach number flow in the combustor the right side of equation (1) (source forcing function) $\varphi_{3, w}$ from Ref. 27 may be written as

$$
\therefore \varphi_{3, \omega}=-\frac{\dot{W}}{A} \frac{\delta}{\rho} \frac{{ }_{V_{0}{ }^{n}{ }_{c} \ddot{H}_{v} f_{0}{ }^{2}}}{C_{p}{ }_{T}{ }_{T, 0}} e^{-\lambda\left(x-L_{\hat{O}}\right)}
$$

the solution of equation (1) with source term expression (2) is accomplished using the Greens function. First the duct is divided into two regions: one, upstream of a point source located in the source region and the other downstream of the point source. Complex reflection factors are def ined and the method used for solving the wave equation for a string with source and reflecting points is followed as given in Ref. 28 (page 132-138) (see Appendix $B$ for the derivation). The equation for the acoustic pressure in the downstream region is from Appendix B (Eqs. (B15) and (B16)):

$$
\begin{aligned}
& P_{\omega, t}=-i{ }^{n_{p}} \frac{\dot{w}}{\bar{A}} \frac{{ }^{\delta} \omega}{\rho} \frac{V_{0}{ }^{n} c^{H_{v}} f_{0} \lambda^{2}}{C_{p}{ }^{\top}{ }_{T 0} k_{T}} \\
& x\left[e^{i k_{T}(\ell-x)}+R_{T} e^{-i\left[k_{T}(l-x)-\phi_{T}\right]}\right] \\
& x \int_{0}^{L_{0}+L_{b}}\left[\frac{e^{i k_{0} x_{0}}+R_{0} e^{-i\left(k_{0} x_{0}-\phi_{0}\right)}}{F_{0}\left(x_{0}\right)}\right] e^{-\lambda\left(x_{0}-L_{0}\right)} d x_{0}
\end{aligned}
$$

where the denominator in the integral is

$$
\begin{array}{r}
F_{0}\left(x_{0}\right)=\frac{k_{0}}{k_{T}}\left[e^{i k_{0} x_{0}}-R_{0} e^{-i\left(k_{0} x_{0}-\phi_{0}\right)}\right]\left[e^{i k_{T}\left(l-x_{0}\right)}\right. \\
\left.+R_{T} e^{-i\left[k_{T}\left(l-x_{0}\right)-\phi_{T}\right]}\right]+\left[e^{i k_{T}\left(l-x_{0}\right)}\right. \\
\left.-R_{T} e^{-i\left[k_{T}\left(l-x_{0}\right)-\phi_{T}\right]}\right]\left[e^{i k_{0} x_{0}}+R_{0} e^{-i\left(k_{0} x_{0}-\phi_{0}\right)}\right]
\end{array}
$$

This equation was programmed and integrated numerically over the combustion zone using a computer. The output of the program was the power spectral density of the acoustic pressure.

For comparison purposes the acoustic pressure calculated for the same combustion noise source but in an infinite duct is, from Ref. 27:

$P_{\omega, R}$

$=\frac{-i}{2} n_{p} \frac{\dot{W}}{\bar{A}} \frac{\delta \omega}{\rho} \frac{V_{0} n_{c} H_{v} f_{0} \lambda^{2} e^{-i k x}}{C_{P} T_{T O}{ }^{T}} \int_{L_{0}^{L_{0}+L_{b}}}^{e^{-(\lambda-i k) x_{0}}} d x_{0}$

It can be shown that for equal wave numbers

$\left(k_{T}=k_{0}\right)$ and for both reflection factors and phase angles equal zero, equation. (3) reduces exactly to equation (5) as might be expected.

\section{Trends Predicted From Theory}

The acoustic pressure as a function of frequency has been: caiculated using Eqs. (3) and (4). This calculation accounts for reflections from the turbine and the combustor inlet. An acoustic pressure efficiency using infinite tube theory, was calculated in Ref. 27 using fluctuating pressure data measured in a CF $6-50$ turbofan combustor at the 3.8 percent thrust level. 7 
The acoustic pressure efficiency as determined in Ref. 27 was 0.045 . However, due to the omission of a radical in the equation used to calculate the acoustic pressure efficiency in Ref. 27 and because of terms in the frequency parameter, a corrected value of 0.088 has been used with the present theoretical calculations. The narrowband data, used herein were analyzed using a two Hertz bandwidth filter. All theoretical pressure spectra for comparison purposes have been multiplied by the two Hertz bandwidth so that they are directly comparable with the as analyzed data reported in Ref. 7 .

\section{Measurement Location Effects}

The measured fluctuating pressure spectrum reported in Ref. 7 was obtained at the borescope opening in the combustor just downstream of the combustor inlet station. Figure 3 shows the theoretical pressure spectrum at 100 percent thrust for duct measurement locations $x / \ell=0.1$ through 0.4 with the same reflection factor $(R=0.35)$ and phase shift $(\phi=\pi / 2)$ at both reflecting planes. Little difference exists below $1000 \mathrm{~Hz}$ over the range of axial locations shown (see Fig. 3 ); however, significant difference exists above $1000 \mathrm{~Hz}$.

\section{Reflection Factor Effect}

The magnitude of the reflection factor has a large effect on the spectral shape as shown in $\mathrm{Fig} .4$ for the CF6-50 combustor operating at 100 percent thrust. Figure $4(a)$ presents the theoretical narrowband pressure spectrum at $x / \ell=0.2$ for equal reflection factors from $R=0.0$ to 0.8 and a phase angle, $\phi=\pi / 2$ radians. Large changes of the spectral shape are noted with changes of $R$ in this range. For complete reflection, (Fig. $4(\mathrm{~b})$ ), $R_{T}=R_{0}=1$, the resonant frequency calculated from $f=C / 4 l$ for the upstream and downstream sonic velocities respectively are on the order of 386 and $529 \mathrm{~Hz}$ where the values are calculated by treating the combustor as if it were entirely cold or entirely hot respectively. Within this range of frequencies several oscillations occur in the spectra. As will be shown later the lower values of the reflection factor appear to be more representative of the data.

Variation of the phase angle associated with the reflection factor, as shown in Fig. 5, has a significant effect on the narrowband spectral shape. Figure 5 presents the theoretical pressure spectrum at the CF6-50 engine 100 percent thrust condition. The reflection factors are equal with magnitude $R_{T}=R_{0}=0.35$ and equal but varying phase angles. The variation of the phase angle, $\phi=0$ through $2 \pi$ radians, causes !large changes in the spectral shape. All spectra are double humped in the frequency range shown. It appears that more exact knowledge of the phase angle is required if one expects to accurately predict the effect of reflections on combustion generated noise spectra as obtained from combustor pressure measurements.

\section{Comparison of Combustor Data With Theory}

The narrowband fluctuating pressure spectra from Ref. 7 are shown in Fig. 6 along with the spectra predicted by the present theory. A range of operating conditions from 99.9 percent to 3.8 percent of design thrust are shown, (Fig. 6 (a) through $6(d)$, respectively). As discussed in
Ref. 8 the measured spectra above idle setting are bi-lobed with maximums occurring in frequency regions of 350 and 1100 to $1300 \mathrm{~Hz}$. The theoretical spectra were calculated for $R_{T}=R_{0}=0.35$ and $\phi=\pi / 2$ and are shown in Fig. 6 by the solid lines. Also shown in Fig. 6 are the calculated spectra for reflection factor equal zero (dashed line). Reference 29 indicates that reflection factors on the order of 0.4 might be expected from turbines.

The theory predicts two humps in the spectra, one centered in the frequency range between 200 and $.700 \mathrm{~Hz}$ and the other centered in the frequency range 1000 to $1600 \mathrm{~Hz}$. The predicted humps, above idle condition, appears to occur at a higher frequency than the humps in the data by 100 to $200 \mathrm{~Hz}$. Comparisons of the theoretical hump center frequency with increasing engine speed above idle shows that it is predicted to increase with speed. The experimental data also show increasing hump center frequency with increasing engine speed. The shape of the theoretical spectra and data also show similar trends with frequency. It has been shown that reflection factor phase angles and, at the higher frequencies, the measurement location have significant effect on the spectral shape. Even though the real phase angles and measurement location are not known precisely it appears that the agreement between theory and experiment is adequate. Taking into account the stated uncertainties the conclusion is drawn that the deviation of the spectral data above idle conditions from the simple source noise given in Ref. 27 may be attributed to reflections from the turbine and combustor inlet.

At idle condition (Fig. 6(d)), the theoretical pressure spectrum with reflection factors of zero (see dashed line Fig. 6(d)) agree with the experimental data. The data does not show a distinct peak in the spectrum where it might be expected if reflections were significant. Reference 29 indicates that the turbine reflection should decrease with turbine pressure ratio. Hence, at the 3.8 percent thrust level the turbine reflection factor should approach zero. Judging from the lack of humps in the spectra at the 3.8 percent thrust level it appears that little or no reflection exists in the combustor at idle speed and indeed the turbine reflection factor is zero. As has been shown in Ref. 27 the infinite tube theory predicts the narrowband spectrum in the CF6-50 combustor very well at the idle condition.

\section{Concluding Remarks}

The present analysis neglects the effects on the acoustic pressure measured between the reflecting planes of both area variation between reflecting planes and acoustic wave number variation within the combustion zone. The analysis in Refs. 25 and 26 includes these effects. However, the present analysis does include the effect of a distributed source. Certain conclusions may.still be drawn from the present analys is that appear to explain some of the variations in the spectra from the simple combustion noise source derived in Ref. 27.

It has been shown that reflections from the turbine and combustor inlets are the probable cause for the deviation of the combustor fluctuating pressure spectra from the smooth curve. given by the source spectrum. Since the strongest reflected 
wave interference with the source can only exist between the reflecting planes one may conclude that the source wave itself will dominate and essentially be transmitted through the reflecting planes without spectral shape modification. Of course the magnitude of the source wave will be decreased but the frequency dependence should remain the same. For this reason one may expect that the acoustic pressure measured external to an engine in the far field will have the very low frequency dominated spectrum of the combustion noise source as reported in Ref. 27. Cross correlations between combustor and $f$ ar-field microphones verify this conclusion. 8

\section{Conclusions}

A theoretical investigation of the effect on combustion chamber fluctuating pressures of reflecting planes at the combustor and turbine inlet locations has been performed. The pressure spectrum has been calculated and compared to existing data from a CF6-50 turbofan engine combustor and found to be in substantial agreement. The following conclusions have been drawn from the theory and comparisons of the theory with data.

1. At idle engine speed no reflection from the turbine or combustor inlet occur and the infinite tube theory applies and yields excellent agreement with the data.

2. Above engine idle conditions, reflections from the turbine and combustor inlets occur and reasonable agreement between theory and narrowband combustor pressure spectra has been found using a reflection factor on the order of 0.35 and a phase angle of $\pi / 2$ radians.

3. Measured spectrum shape is independent of the measurement location at low frequencies, but not at the high frequencies.

\section{Appendix A}

\section{Symbols}

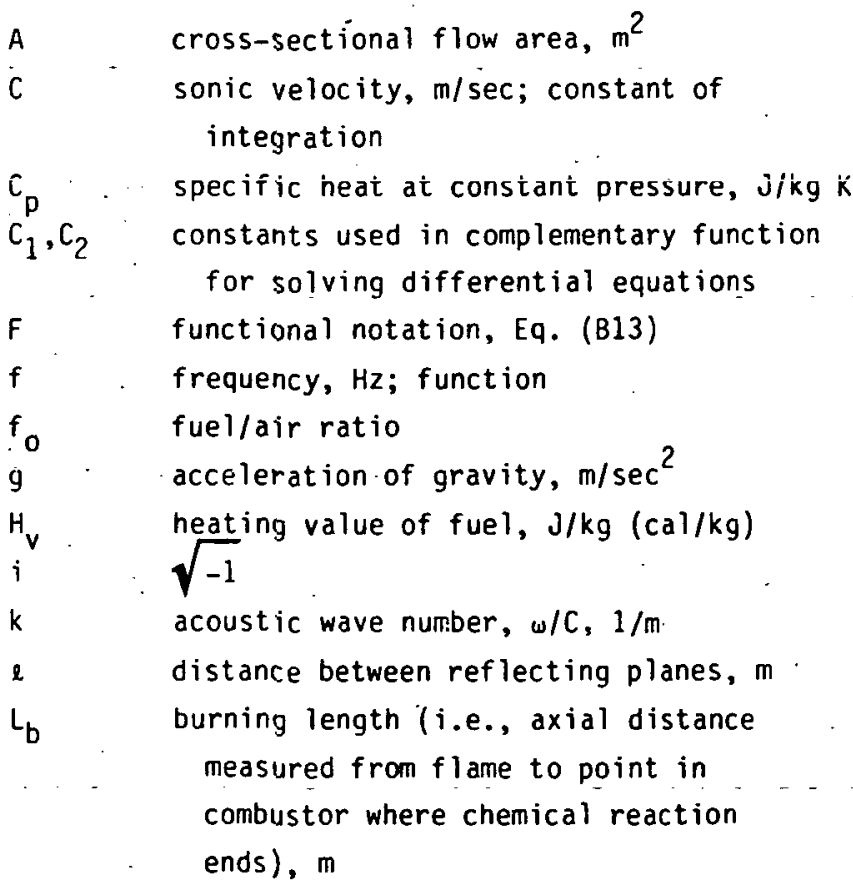

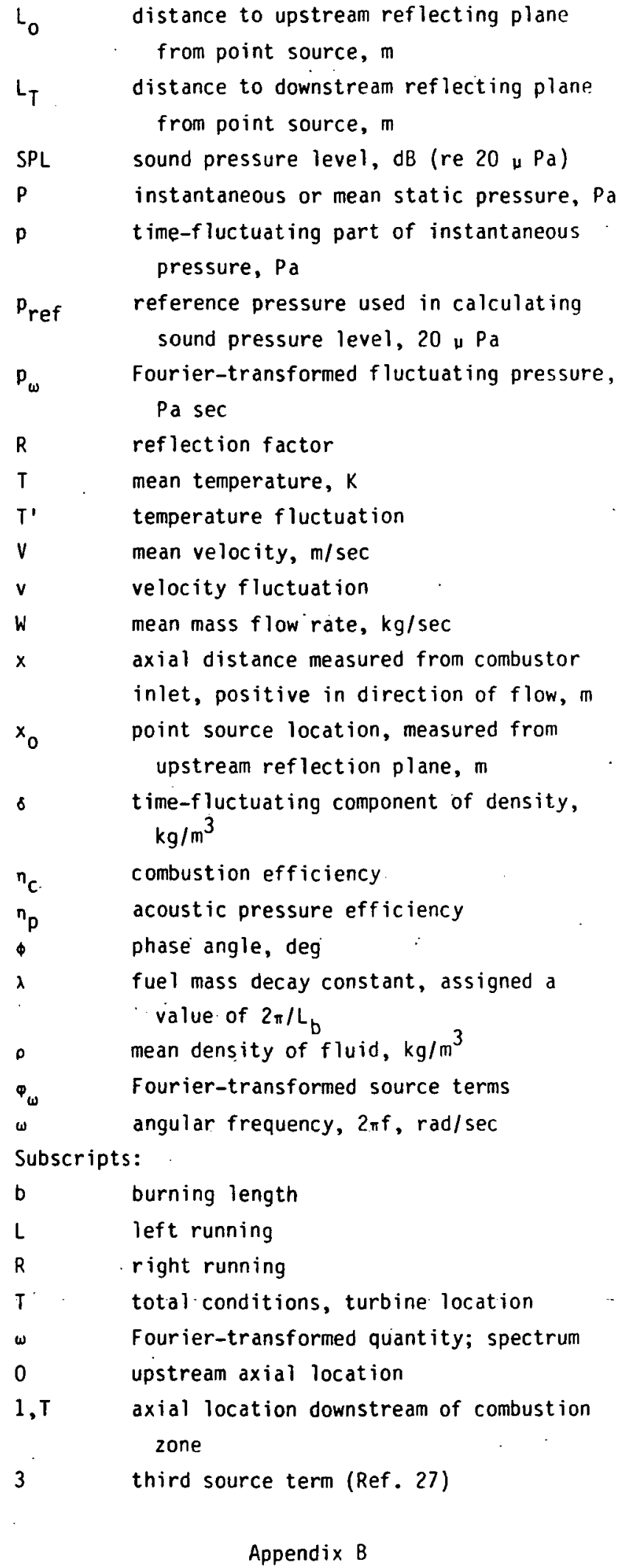

Solution of the One-Dimensional, Fourier Transformed Acoust ic Wave Equation with Combustion No ise Source Term and Two Reflecting Planes

The acoustic wave equation governing the acoustic pressure generated and measured in a one-dimensional duct with reflecting planes. 
representing the combustor and turbine inlets is, from Ref. 27:

$$
\frac{\partial^{2} p_{\omega}}{\partial x^{2}}+k^{2} p_{\omega}=-\Phi_{3, \omega}
$$

where the source term $\varphi_{3, \omega}$ is given in Ref. 27 as:

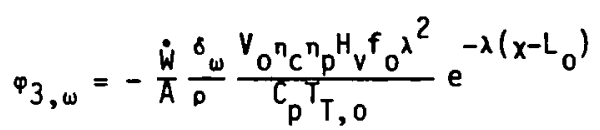

The homogeneous equation obtained by setting to zero is

$$
\frac{\partial^{2} p_{\omega}}{\partial x^{2}}+k^{2} p_{\omega}=0
$$

The solution of equation (B3) is

$$
P_{\omega, 0}=c_{1} e^{i k x}+c_{2} e^{-i k x}
$$

$\underset{\text { Wave Pressure }}{\text { Resultant }}=\begin{aligned} & \text { Left Running } \\ & \text { Wave Pressure }\end{aligned}+\begin{aligned} & \text { Right Running } \\ & \text { Wave Pressure }\end{aligned}$

A point or planar source is assumed to exist in the combustion zone. The regions between the point source and the combustor inlet and the point source and the turbine inlet have different temperatures and hence different sonic velocities and fluid properties. At the combustor inlet reflecting plane $(x=0)$ the reflection factor, a complex number., defined as the complex ratio of the reflected to the incident acoustic pressures, is given by:

$$
\frac{p_{\omega, R}}{p_{\omega, L}} \equiv R_{0} e^{i_{\phi_{0}}}
$$

and at the turbine reflecting plane, $(x=\ell)$.

$$
\frac{p_{\omega, L}}{p_{\omega, R}} \equiv R_{T} e^{i_{\phi}}
$$

The magnitude and phase of both reflection factors are assumed to be constant and known quantities.

The two regions are treated separately until later in the derivation. In the region upstream of the point source equation (B4) may be written in terms of the combustor inlet reflection factor as: $p_{\omega, 0}=C_{1}\left[e^{i k_{0} x}+R_{0} e^{-i\left(\cdot k_{0} x-\phi_{0}\right)}\right], 0<x<x_{0}<\varepsilon$

In the region downstream of the point source the acoustic pressure again written in terms of the turbine reflection factor is:

$$
\begin{array}{r}
p_{\omega, T}=C_{2}\left[R_{T} e^{-i\left[k_{T}(l-x)-\phi_{T}\right]}+e^{i k_{T}(l-x)}\right], \\
0<x_{0} \leq x<\ell
\end{array}
$$

The method used in Ref. 28 for solving the harmonically driven string with reflections is now applied to find the solution of the acoustic wave equation used herein. Equations (B7) and (B8) have two unknown constants, $C_{1}$ and $C_{2}$. Therefore two bits of information are required to solve for these constants. The first requirement is that the pressures across the point source are continuous, i.e., pressures at the source are equal for both regions. Equating equation (B7) to equation (B8) at the source location, $x=x_{0}$ yields

$c_{1}\left[e^{i k_{0} x_{0}}+R_{0} e^{-i\left(k_{0} x_{0}-\phi_{0}\right)}\right]$

$-C_{2}\left[R_{T} e^{-i\left[k_{T}\left(l-x_{0}\right)-\phi_{T}\right]}+e^{i k_{T}\left(l-x_{0}\right)}\right]=0$

From Ref. 28 the difference in the slopes at the point source is minus one. Taking the derivative with respect to $x$ of Eqs. (B7) and (B8), equating the differences of the slopes to -1 yields the second expression in terms of $C_{1}$ and $C_{2}$ as:

$$
\begin{aligned}
& c_{1} i k_{0}\left[e^{i k_{0} x_{0}}-R_{0} e^{-i\left(k_{0} x_{0}-\phi_{0}\right)}\right] \\
& +c_{2} i k_{T}\left[e^{i k_{T}\left(l-x_{0}\right)}-R_{T} e^{-i\left[k_{T}\left(l-x_{0}\right)-\phi_{T}\right]}\right]=-1
\end{aligned}
$$

Solving Eqs. (B9) and (B10) for $C_{1}$ and $C_{2}$ and substituting $C_{1}$ and $C_{2}$ into Eqs. (B7) and (B8) respectively yields the expression for the acoustic pressure that would be measured in the duct if the duct were forced by the unit impulse function. The resulting acoustic pressures for the two regions are: 


$$
\begin{aligned}
& p_{\omega, 0}=\frac{i_{k_{T}}\left[e^{i k_{0} x}+R_{0} e^{-i\left(k_{0} x-\phi_{0}\right)}\right]\left[e^{i k_{T}\left(\ell-x_{0}\right)}+R_{T} e^{-i\left[k_{T}\left(l-x_{0}\right)-\phi_{T}\right]}\right]}{F_{0}\left(x_{0}\right)} \\
& 0<x<x_{0}<2
\end{aligned}
$$

and

$$
\begin{aligned}
& p_{w, T}=\frac{i \frac{i}{k_{T}}\left[e^{i k_{T}(\ell-x)}+R_{T} e^{-i\left[k_{T}(\ell-x)-\phi_{T}\right]}\right]\left[e^{i k_{0} x_{0}}+R_{0} e^{-i\left(k_{0} x_{0}-\phi_{0}\right)}\right]}{F_{0}\left(x_{0}\right)} \\
& 0<x_{0}<x<2
\end{aligned}
$$

where the denominator is a function of the point source location and is given by:

$$
\begin{aligned}
F_{0}\left(x_{0}\right)=\frac{k_{0}}{k_{T}}\left[e^{i k_{0} x_{0}}-R_{0} e^{-i\left(k_{0} x_{0}-\phi_{0}\right)}\right] \\
x \\
+\left[e^{i k_{T}\left(l-x_{0}\right)}+R_{T} e^{-i\left[k_{T}\left(l-x_{0}\right)-\phi_{T}\right]}\right] \\
+\left[e^{i k_{T}\left(l-x_{0}\right)}-R_{T} e^{-i\left[k_{T}\left(l-x_{0}\right)-\phi_{T}\right]}\right] \\
\times\left[e^{\left.i k_{0} x_{0}+R_{0} e^{-i\left(k_{0} x_{0}-\phi_{0}\right)}\right]}\right.
\end{aligned}
$$

Having the solutions for the acoustic pressure, in their respective regions as a response to the unit impulse function the acoustic pressure in the duct as a response to the distributed source in the combustion region can be found by integrating the product of the source $\varphi_{3}$ and the pressure response to the unit impulse function over the combustion region as discussed in Ref. 28 . In equation form the pressure in the upstream region is:

$$
\begin{aligned}
& p_{\omega, 0}=\frac{i}{k_{T}}\left[e^{i k_{0} x}+R_{0} e^{-i\left(k_{0} x-\phi_{0}\right)}\right] \times \int_{x_{0}=L_{0}}^{x_{0}=L_{0}+L_{b}} \\
& {\left[\frac{e^{i k_{T}\left(l-x_{0}\right)}+R_{T} e^{-i\left[k_{T}\left(l-x_{0}\right)-\phi_{T}\right]}}{F_{0}\left(x_{0}\right)}\right] \cdot \Phi_{3, \omega}\left(x_{0}\right) d x_{0}} \\
& 0<x<x_{0}<\ell
\end{aligned}
$$

In the downstream region:

$$
\begin{gathered}
p_{\omega, T}=\frac{i}{k_{T}}\left[e^{i k_{T}(\ell-x)}+R_{T} e^{-i\left[k_{T}(l-x)-\phi_{T}\right]}\right] x \int_{x_{0}=L_{0}}^{x_{0}=L+L_{0} b} \\
{\left[\frac{e^{i k_{0} x_{0}}+R_{0} e^{-i\left(k_{0} x_{0}-\phi_{0}\right)}}{F_{x}\left(x_{0}\right)}\right] \cdot \Phi_{3, \omega}\left(x_{0}\right) d x_{0}} \\
0<x_{0}<x<\ell
\end{gathered}
$$

where $F_{0}\left(x_{0}\right)$ is given by equation (B13) and the source term from Ref. 27 is given by

$$
\varphi_{3, \omega}=-\frac{\dot{W}}{A} \frac{\delta}{\rho} \frac{V_{0}{ }^{n} p^{n} c^{H_{v} f_{0} \lambda^{2}}}{C_{p} T_{0}} e^{-\lambda\left(x_{0}-L_{0}\right)}
$$

The integration is performed by converting from the complex polar form to the complex rectangular form, integrating the real and imaginary parts separately, and then converting the results of the integration back to polar form. Numerical integration was used in the present work. The pressure calculated using Eq. (B15) and expression (B16) is the theoretical acoustic pressure in the duct for the region downstream of the point source. It was used in making the theoretical acoustic pressure predictions reported herein since the data used for comparison was taken from a sensor located downstream of the expected flame front location.

\section{References}

1. Huff, R. G., Clark, B. J., and Dorsch, R. G. "Interim Prediction Method for Low Frequency Core Engine Noise," NASA TM X-71627, 1974.

2. Emmerling, J. J., "Experimental Clean Combustor Program; Noise Measurement Addendum, Phase I," General Electric Co., Cincinnati, OH, GE75AEG315, July 1975. (NASA CR-134853). 
3. Sofrin, T. G., and Ross, D. A., "Noise Addendum, Experimental Clean Combustor Program, Phase I," Pratt \& Whitney Aircraft, East Hartford, CT, PWA-5252, 0ct. 1975. (NASA CR-CR-134820).

4. Emmerling, J. J., and Bekofske, K. L., "Experimental Clean Combustor Program; Noise Measurement Addendum, Phase II," General Electric Co., Cincinnati, OH, R75AEG147-13-ADD, Jan. 1976. (NASA CR-CR-135045).

5. Sofrin, T. G., and Riloff, N., Jr., "Experimental Clean Combustor Program: Noise Study," Pratt \& Whitney Aircraft, East Hartford, CT, PWA-5458, Sept. 1976. (NASA CR-135106).

6. Doyle, V. L., "Experimental Clean Combustor Program, Phase III: Noise Measurement Addendum, "General Electric Co., Cincinnati, OH, R78AEG319, Dec. 1978. (NASA CR-159458).

7. Doyle, V. L., "Core Noise Investigation of the CF6-50 Turbofan Engine," General Electric Co., Cincinnati, OH, R79AEG247, Jan. 1980. (NASA CR-159598).

8. Doyle, V. L., and Moore, M. T., "Core Noise Investigation of the CF6-50 Turbofan Engine, Final Report," General Electric Co., Cincinnati, OH, R79AEG395, Jan. 1980. (NASA (R-159749).

9. Wilson, C. A., "YF102 In-Duct Combustor Noise Measurement, "Vols. I, II and III," AVCO Lycoming Div., Stratford, CT, LYC-77-56-VOL-1, VOL-2-VOL-3, Nov. 1977. (NASA CR-135404-VOL-1, VOE-2, VOL-3).

10. Woodward, R. P., and Minner, G. L., "LowFrequency Rear Quadrant Noise of a Turbojet Engine with Exhaust Duct Muffling," NASA TM $\mathrm{X}-2718,1973$.

11. Burdsall, E. A., Brochu, F. P., and Scaramella, V. M., "Results of Acoustic Testing of the JT8D-109 Refan Engines," Pratt \& Whitney Aircraft, East Hartford, CT, PWA 5298, Nov. 1975. (NASA CR-134875).

12. Mathews, D. C., and Peracchio, A. A., "Progress in Core Engine and Turbine Noise Technology," AIAA Paper 74-948, Aug. 1974.

13. Karchmer, A. M., and Reshotko, M., "Core Noise Source Diagnostics on a Turbofan Engine Using Correlation and Coherence Techniques," NASA TM X-73535, 1976.

14. Reshotko, M., Karchmer, A., Penko, P. F., McArdle, J. G., "Core Noise Measurements on a YF-102 Turbof an Engine," AIAA Paper 77-21, Jan. 1977.

15. Karchmer, A. M., Reshotko, M., and Montegani, F. G., "Measurement of Far Field Combustion Noise from a Turbof an Engine Using Coherence Functions," NASA TM-73748, 1977.
16. Reshotko, M., and Karchmer, A., "Combustor Fluctuating Pressure Measurements in Engine and in a Component Test Facility: A Preliminary Comparison," NASA TM-73845, 1977.

17. Bilwakesh, K. R., et al., "Core Engine Noise Control Program, vols. I, II, and III," General Electric, Cincinnati, $\mathrm{OH}$, FAA-RD-74-125-VOL-1, VOL-2, VOL-3, Aug. 1974. (Vol. I, AD-A013128/4; Vol. II, AD-A013129/2; Vol. III, $A D-A 013131 / 8$.)

18. Matta, R. K., Sandusky, G. T.; and Doyle, V. L., "GE Core Engine Noise Investigation, Low Emission Engines," General Electric Co., FAA-RD-77-4, 1977, Feb. 1977. (AD-A048590.)

19. Mathews, O. C., Rekos, N. F., Jr.; and Nagel, R. T., "Combustion Noise Investigation Predicting Direct and Indirect Noise from Aircraft Engines," Pratt \& Whitney Aircraft Group, PWA-5478. Feb. 1977. (AD-A038154/1.)

20. von Giahn, U. H., "Correlation of Combustor Acoustic Power Levels Inferred from Internal Fluctuating Pressure Measurements," NASA TM-78986, 1978.

21. Chiu, H. H., and Summerfield, M., "Theory of Combustion Noise," Princeton University, AMS-1136, July 1973. (AD-AA001108.)

22. Muthukrishnan, M., Strahle, W. C., and Handley, J. C., "The Effect of Flame Holders on Combustion Generated Noise," AIAA Paper 76-39, Jan. 1976.

23. Hassan, H. A., "Scaling of CombustionGenerated Noise," Journal of Fluid Mechanics, Vo1. 66, Nov. 25, 1974, pp. 445-453.

24. Stephenson, J., and Hassan, H. A., "The Spectrum of Combustion-Generated Noise," Journal of Sound and Vibration, Vol. 53, July 22, 1977, pp. 283-288.

25. Mahan, J. R., and Kasper, J. M., "Influence of Heat Release Distribution on the Acoustic Response of Long Burners," ASME Paper 79-OET-31, Sept. 1979.

26. Miles, J. H., and Krejsa, E. A., "A Theoretical Model for the Cross Spectra Between Pressure and Temperature Downstream - of a Combustor," 107th Acoustical Society of America Meeting, Norfolk, VA, Journal of the Acoustical Society of-America, Suppl. 1, VoT. 75, May 1984. (NASA TM-8367)'

27. Huff, Ronald G., "Simplified Combustion Noise Theory Yielding a Prediction of Fluctuating Pressure Level," NASA TP-2237, 1984.

28. Morse, Philip M., and Ingard, K. Uno., "Theoretical Acoustics, McGraw-Hill Book Co., New York, 1968.

29. Matta, R. K., and Mani, R., "Theory of Low Frequency Noise Transmission Through Turbines," General Electric Co., Cincinnati, OH, R77AEG570, Mar. 1979. (NASA CR-159457). 

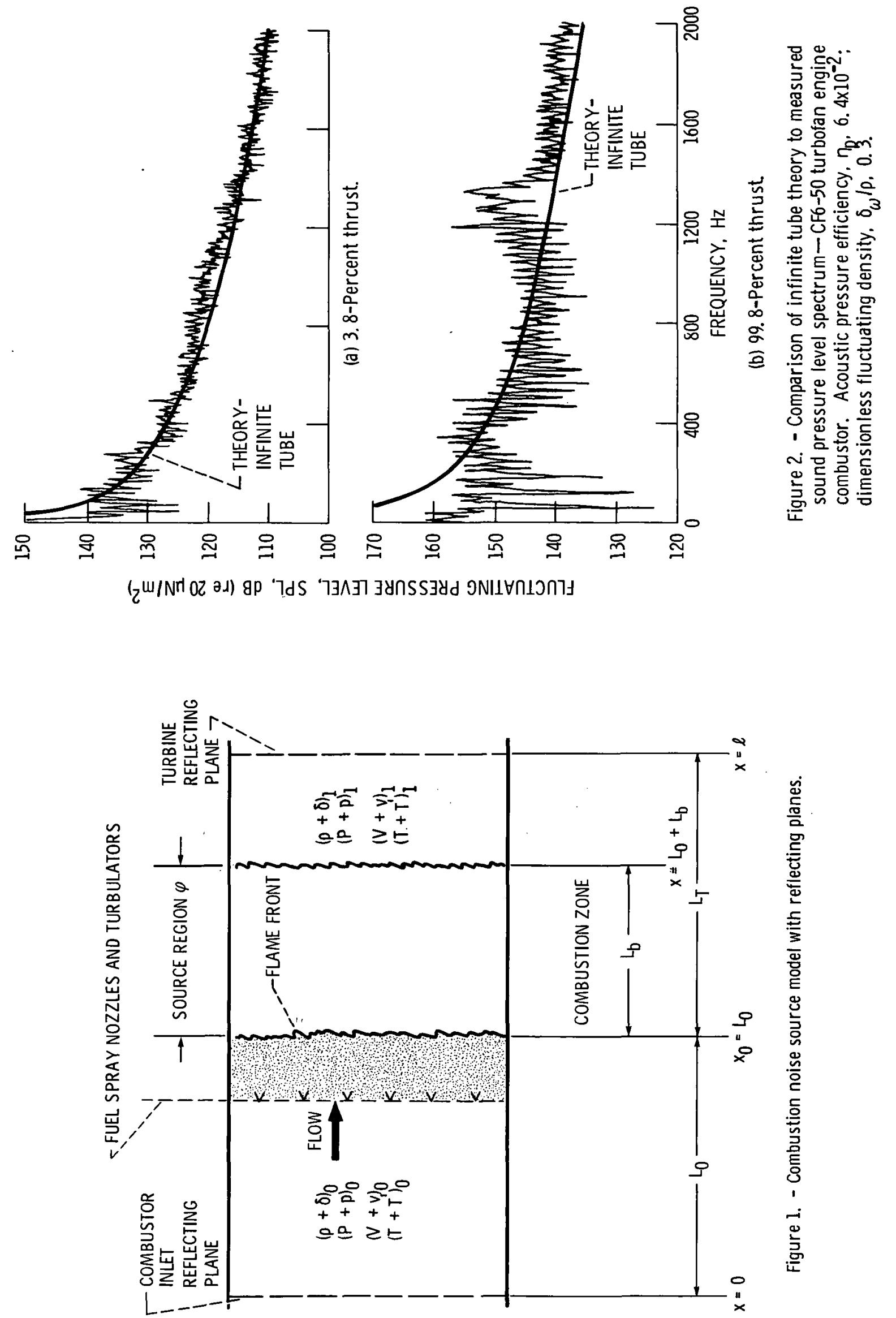


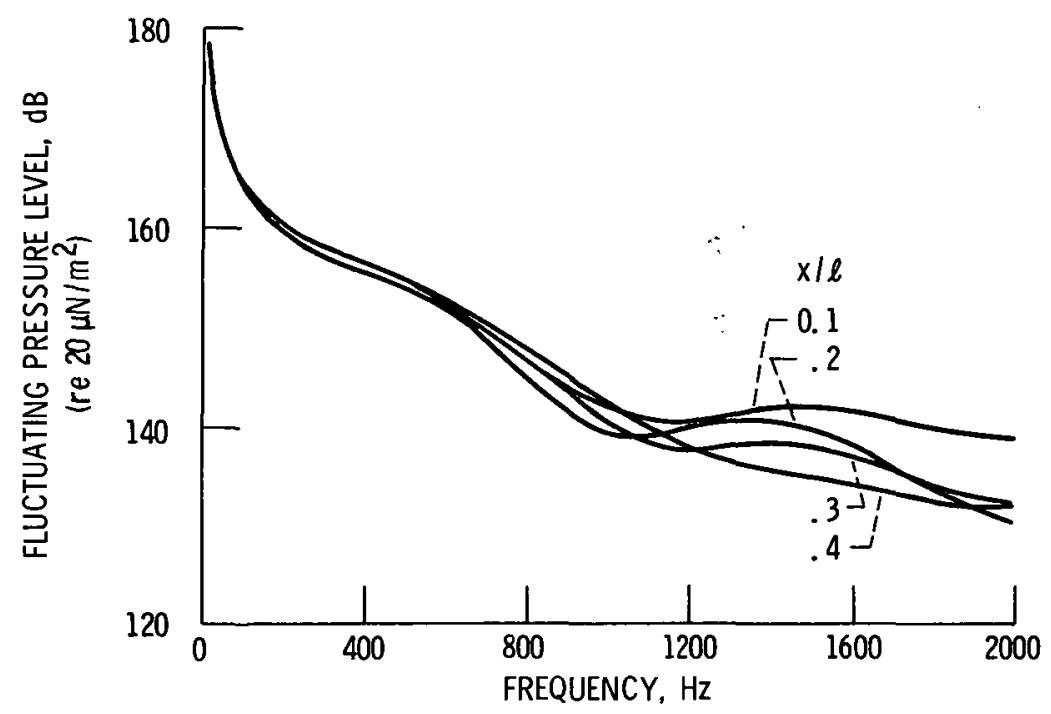

Figure 3. - The effect of measurement location on acoustic pressure spectrum calculated from theory: 99. 9-percent thrust, CF6-50 turbofan operating condition, equal phase angles $(\Phi=\pi / 2)$ and reflection factors $(R 1=0.35), L_{0} / \ell=$ $0.18, L_{T} / 2=0.82, L_{\mathrm{b}} / 2=1.00,2=0.318 \mathrm{~m}, n_{\mathrm{p}}=0.0883$. 


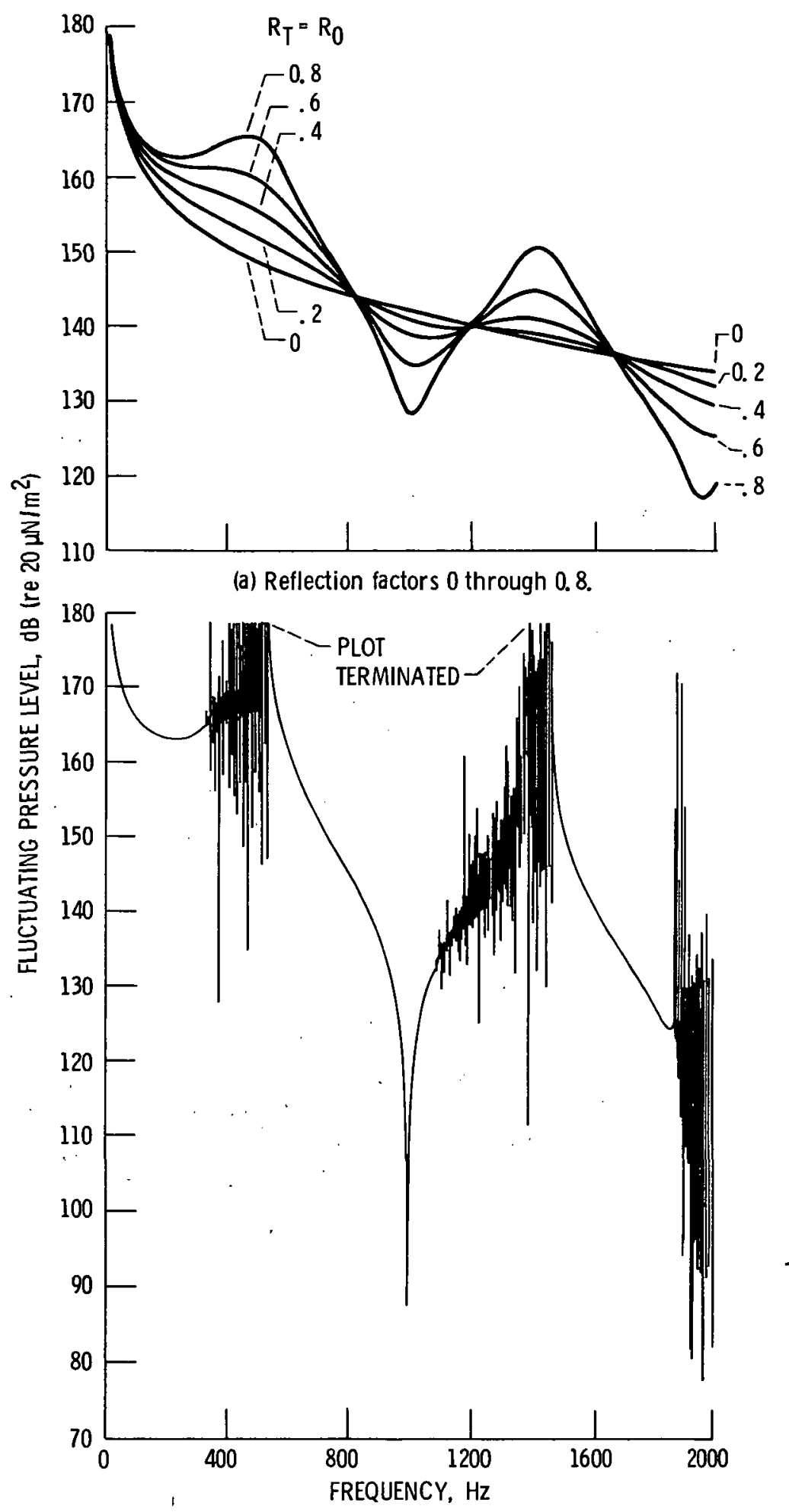

(b) Reflection factor of 1.0 .

Figure 4. - The theoretical effect of reflection factor magnitude on spectral shape for CF6-50 combustor operating at 99. 9percent thrust condition; equal reflection factors and phase angles $(\Phi=\pi / 2 \mathrm{rad}),. L_{0} / \ell=0.18, \mathrm{~L}_{\mathrm{T}} / \ell=0.82, \mathrm{~L}_{\mathrm{b}} / \ell=1.00$, $\ell=0.348 \mathrm{~m}, x / \ell=0.2, \eta_{\mathrm{p}}=0.883$. 


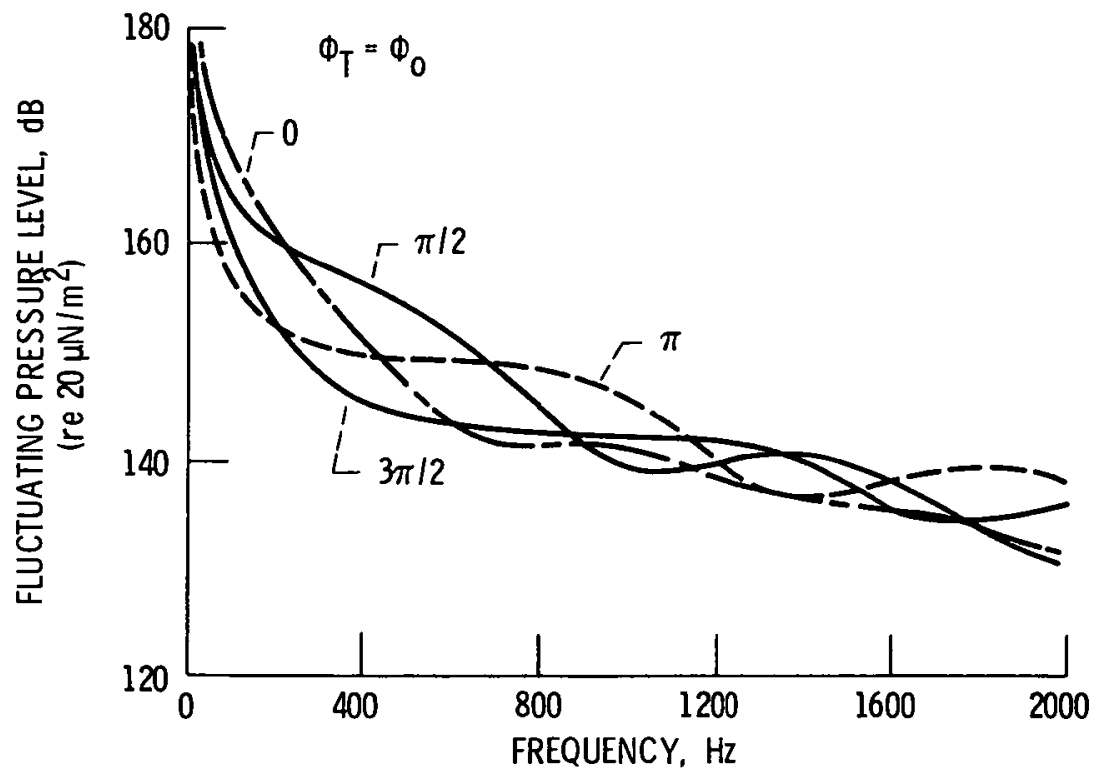

Figure 5. - The theoretical effect of phase angle on spectral shatpe for the $\mathrm{CF} 6-50$ combustor operating at 99. 9-percent thrust level; equal reflection factors $(R=0.35)$ and phase angles: $L_{0} / \ell=0.18 . L_{T} / \ell=0.82 . L_{0} / \ell=1.00, x / \ell=0.20$, $\ell=0.348 \mathrm{~m}, \eta_{\mathrm{p}}=0.0883$. 

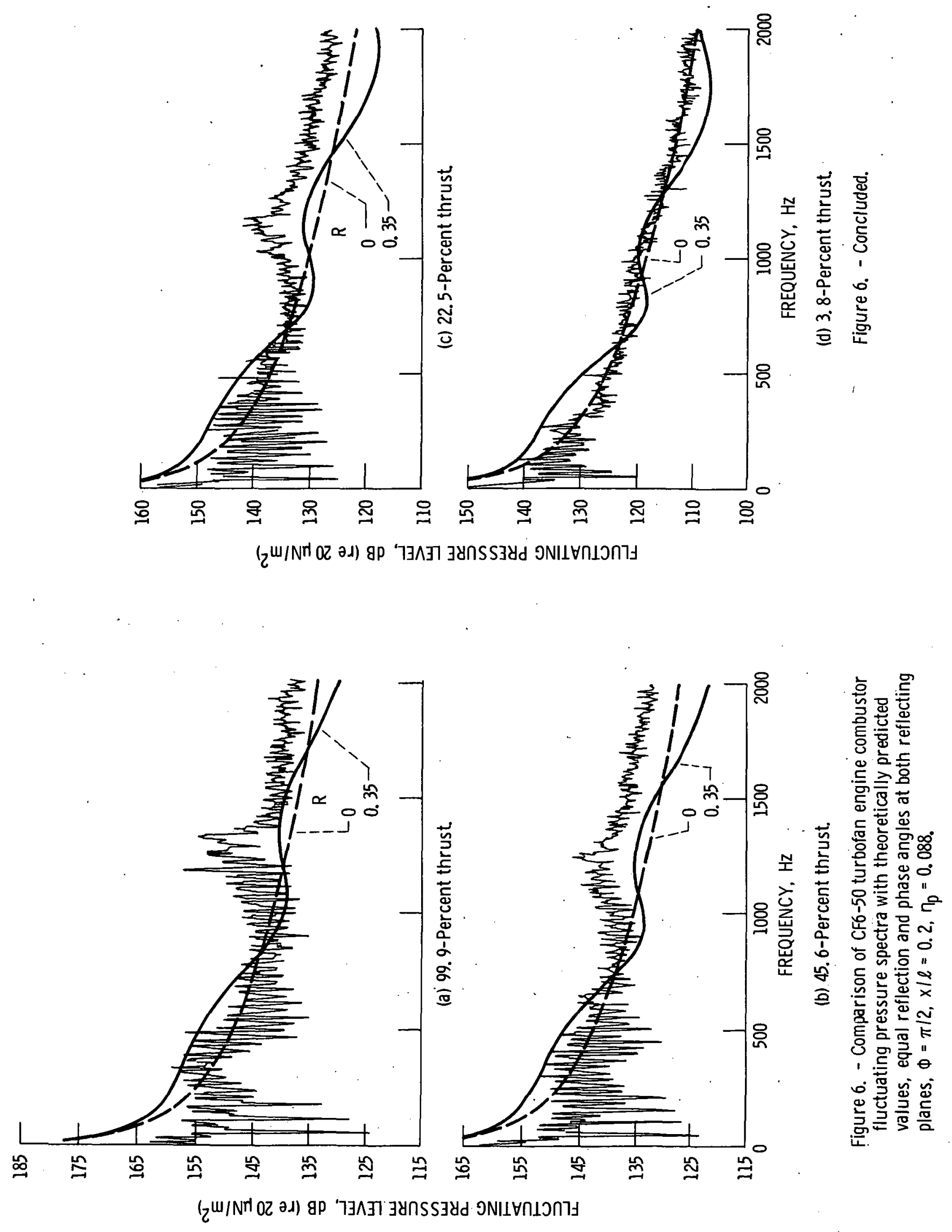


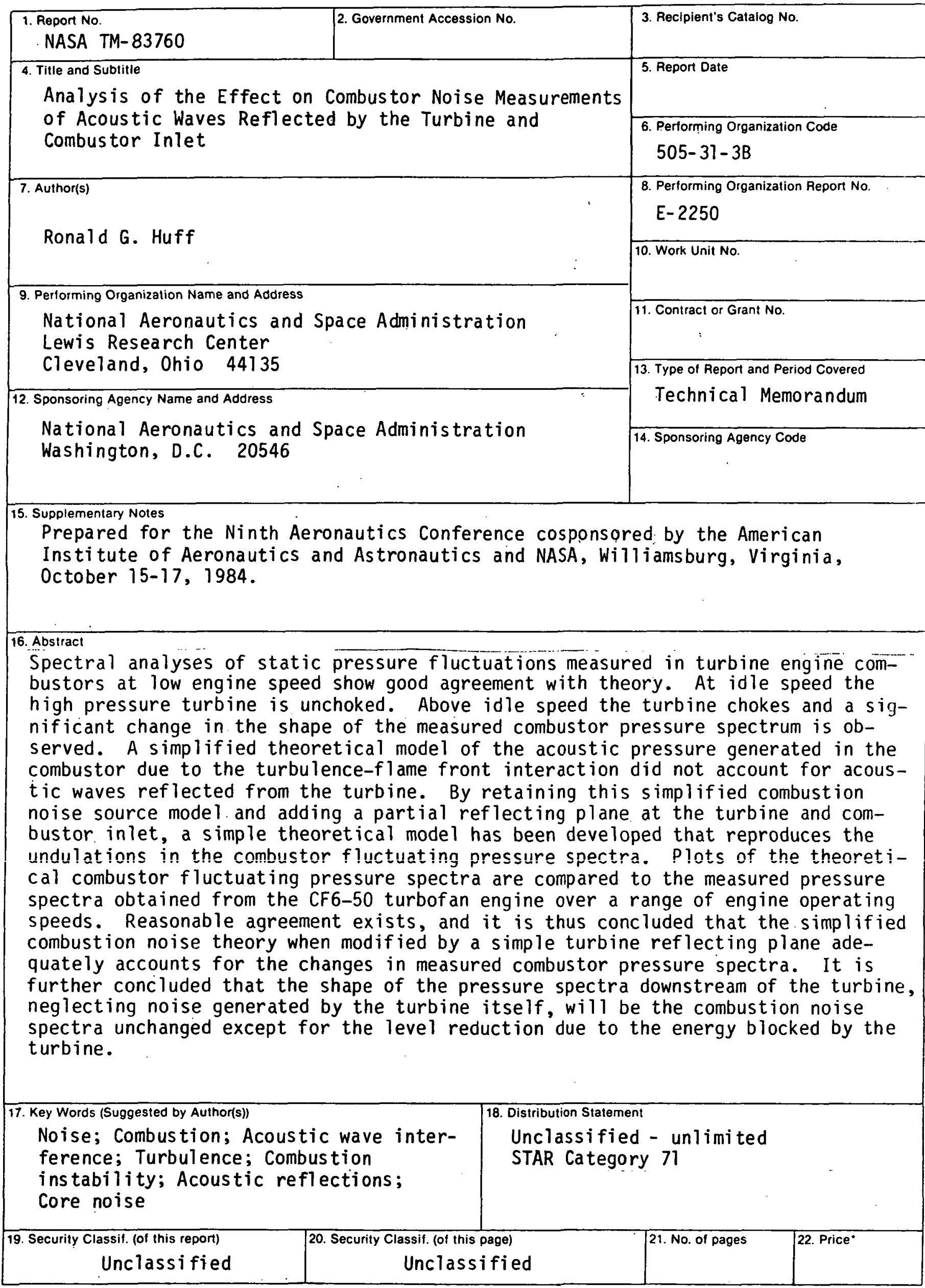

-For sale by the National Technical Information Service. Springfield, Virginia 22161 
National Aeronautics and Space Administration

Washington, D.C.

20546

Official Business

Penalty for Private Use, $\$ 300$
SPECIAL FOURTH CLASS MAIL BOOK

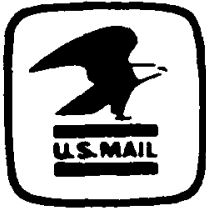

Postage and Fees Paid National Aeronautics and Space Administration NASA-451 